\title{
Design and Implementation of a High Gain Microstrip Antenna Using Antenna Array
}

\author{
Sneha Sharma, Ushma Sharma
}

\begin{abstract}
In this project, the Design of a High Gain Microstrip Antenna using Antenna Array is proposed for wireless applications. The proposed antenna resonates at $5.6 \mathrm{GHz}$ with bandwidth of $500 \mathrm{MHz}$ making it suitable for wireless applications. The proposed antenna is designed on an FR4 substrate with an overall size of $\mathbf{5 0}$ $\mathrm{mm} \times 45 \mathrm{~mm}$. A parametric analysis is performed to understand the resonant behavior of the antenna by changing the size of the patches and the matrix of array. The feeding technique used here is micro strip line feeding.
\end{abstract}

Index Terms - Patch antenna; Wireless Application; Return loss, Radiation pattern; parametric analysis.

\section{INTRODUCTION}

The rapid development of wireless communication technology has increased the demand for compact microstrip antennas with high gain and wideband operating frequencies. Microstrip patch antennas are very advantageous because of their low cost, low profile, light weight and simple realization process. However, the general microstrip patch antennas have some disadvantages such as narrow bandwidth etc. Enhancement of the performance to meet the demanding bandwidth is necessary. There are numerous and well-known methods to increase the bandwidth of antennas, including increase of the substrate thickness, the use of a low dielectric substrate, slotted patch antenna, the use of various impedance matching and feeding techniques. This antenna work on the frequency of $5.6 \mathrm{GHz}$ and the changes are done through changing matrix of the Array.

\section{ANTENNA DESIGN}

The designed antenna work on frequency of $5.6 \mathrm{GHz}$ and the feeding used here is microstrip line feeding. The geometry of proposed high gain microstrip patch antenna using antenna array is shown in Fig 1. All the measurements are in mm. The microstrip patch antenna consists of three layers patch, substrate and ground. Here, the substrate selected for the design of the proposed antenna is FR4_epoxy of thickness 1.6 $\mathrm{mm}$ and with low permittivity $(\boldsymbol{\varepsilon r}=4.4)$. The dimensions of the substrate are taken as $50 \times 45 \times 1.6 \mathrm{~mm}$.

Microstrip patch antennas can be fed by a variety of methods. These methods are classified into two categories which are

Sneha Sharma, Department of Digital communication, Jagannath University, Chaksu, Jaipur (raj.)

Ushma Sharma, Department of Digital communication, Jagannath University, Chaksu, Jaipur (raj.) contacting (direct) and non-contacting. The four most popular feeding techniques used are microstrip feed, co-axial probe feed, aperture coupled and proximity coupled feeding. Here we are doing microstrip line feeding from the bottom face.

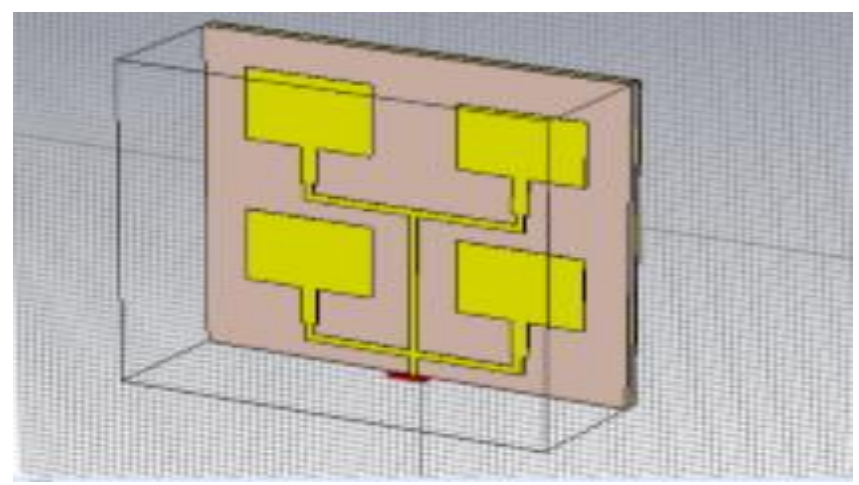

Fig 1- Proposed antenna

In order to understand the complete behavior of the proposed antenna, a parametric analysis is performed by changing the matrix of the array with respective dimensions.

\section{RESULTS}

The simulation results for the proposed antenna are shown in the figures below. The return loss is shown in Fig 2.the sharp cut at the end depict that the output can be consider. The simulated results are well agreed for Wireless applications. The antenna resonates at frequency $5.6 \mathrm{GHz}$. The graph depict the S11 parameter of the antenna and show the value of return loss of the antenna which is -34.85227 which is acceptable result as the value should be smaller than -20 .The achieved bandwidth is good compared to rectangular microstrip antennas operated for Wireless applications. All the results related to the antenna are acceptable during the study.

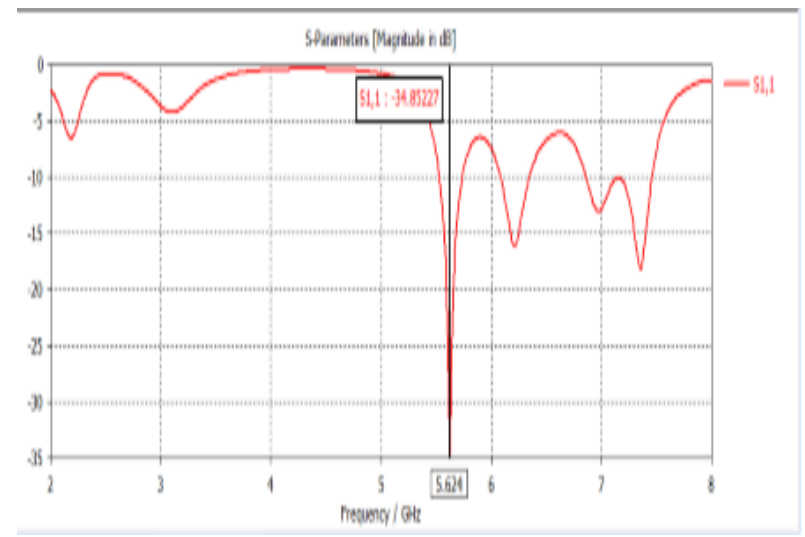

Fig 2 Return Loss 


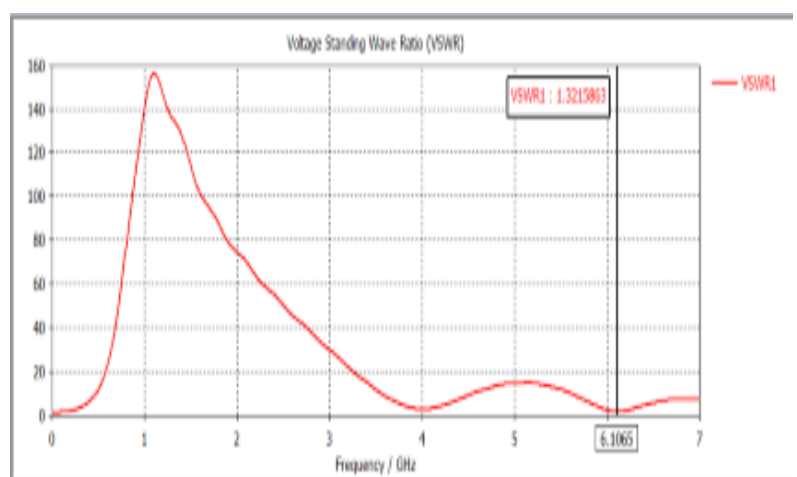

Fig 3 VSWR

Fig 3 Represent the VSWR in designed antenna, the value of VSWR is $\mathbf{1 . 3 6}$. The range of values for VSWR is from 1 to $\infty$. A VSWR value under 2 is considered suitable for most antenna applications. The antenna can be described as having a good match. So when someone says that the antenna is poorly matched, very often it means that the VSWR value exceeds 2 for a frequency of interest. So here the value of VSWR is less than 2 so its value is good.

The explosive growth in the demand for wireless communication and information transfer using handsets and personal communications (PCS) devices has created the need for major advancements of antenna designs as a fundamental part of any wireless system. One type of antennas that fulfills most of the wireless systems requirements is the micro strip antennas. These antennas are widely used on base stations as well as handheld devices. Micro strip antennas have a variety of configurations and are currently the most active field in antenna research and development. The micro strip antennas, due to their great advantages, have increasingly wide range of applications in wireless communication systems as handheld mobile devices, satellite communication systems, and biomedical applications.

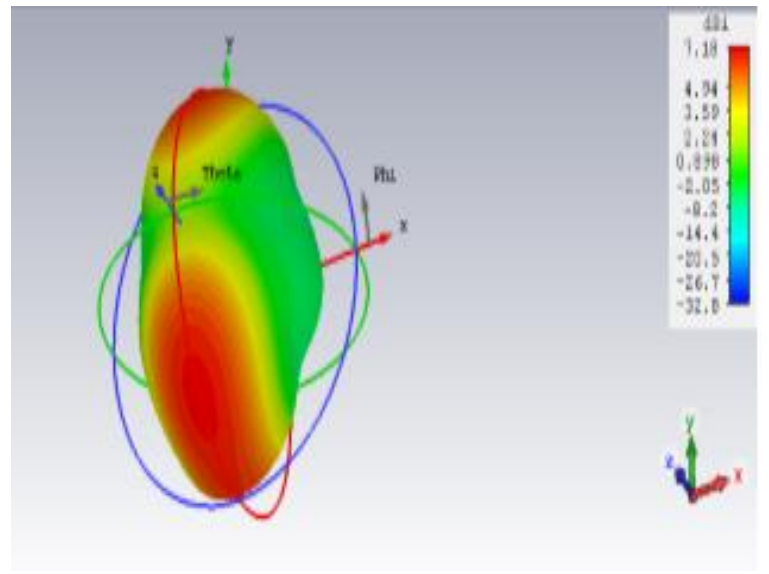

Fig 4 Radiation pattern

In $3 \mathrm{D}$ results, Fig 4 shows the radiation pattern of the antenna with an effective high gain.

\section{CONCLUSION}

A high gain microstrip antenna using antenna array has been designed with the frequency of $5.6 \mathrm{Ghz}$ which have applications in Monitoring System, Wifi Systems, Radio Local Area Network, ISM, WLAN, etc. The different results associated to the designed antenna are shown in the table below.

\begin{tabular}{|l|l|}
\hline Directivity $(\mathrm{dB})$ & 10.18 \\
\hline Gain $(\mathrm{dB})$ & 3.55 \\
\hline Frequency & $5.6 \mathrm{Ghz}$ \\
\hline Return Loss $\{\mathrm{dB}\}$ & -34.89 \\
\hline
\end{tabular}

Table: Results of designed antenna

\section{REFERENCES}

[1] www.antennatheory.com/antennas/patches/antenna.php [2]

www.orbanmicrowave.com/wp-content/uploads/.../Orba n-Patch Antennas-2009-rev.pd

[3] M.Naveena Rama Krishna, M.Sivaji Ganesh, M. Prasanth Kumar Reddy, N.Venkatesh and K. Jagadeesh Babu Dept of ECE, SACET, Chirala, AP, India, International Conference on Electrical, Electronics, Signals, Communication and Optimization (EESCO) 2015

[4] www.slideshare.net/totitarek/microstrip-antenna-154910 7

[5] https://www.microwaves101.com/encyclopedias/microst rip-patch-antennas

[6] staff.bath.ac.uk/eescnm/IEEE/00646798.pdf

[7] ijcsit.com/docs/Volume\%203/Vol3Issue2/ijcsit2012030 248.pdf

[8] citeseerx.ist.psu.eduijcsit.com/docs/Volume\%203/Vol3I ssue2/ijcsit2012030248.pdf 